\title{
DIE ROEPING TOT GEREFORMEERDE GETUIENIS VANDAG, IN WOORD EN GESKRIF TEN OPSIGTE VAN POLITIEKE EN MAATSKAPLIKE GEBIEDE
}

Om Gereformeerd te getuig is om te getuig in die Naam van God. Ons stel die saak onder die volgende vier hoofde:

1. God se rykes - in 'n arm wêreld.

2. God se openbaring - in 'n verwarde en verdwaalde wêreld.

3. God se uitverkiesing en roeping - Sy kerk en Sy getuies.

4. God se wêreld en Sy voleinding.

\section{God se rykes - in 'n arm wêreld}

1.1. Die wêreld dink en praat vandag baie oor ontwikkelde — ryk en daarteenoor onontwikkelde - arm lande en volkere. As Gereformeerde volkie of/en kerkie is ons ons altyd baie bewus van ons armoede, swakheid en kleinheid, in óns land en ook in ander wêrelddele. Ons voel ons so klein teenoor die magtige grootsheid van die wêreld dat ons getuienis maar steeds 'n piepstemmetjie bly, wat maar alte gou afskakel omdat hy oortuig is dat hy tog nie gehoor word nie en elk geval geen drakrag of oortuigingsvermoë besit nie. Daarom is dit noodsaaklik dat ons moet besef dat Gereformeerdheid ' $n$ almagtige miljoenêrsrykdom is, God se rykdom. Teenoor baie minagting en veragting van Gereformeerdheid as sodanig, moet ons besef en vashou dat daar ook hoë agting is en ook waardering, van vriend en vyand, al word dit heel weinig uitgespreek. Ons noem enkeles wat ons raakgeloop het.

Aan die begin van die vyftigerjare, toe Suidwes vir die eerste keer drie in plaas van éên Gereformeerde predikant sou kry, het 'n landmeter afkomstig van Pretoria wat jare in Suidwes gewerk het, die volgende aan ons gesê: „Ek is N.G. gebore en sal dit seker sterf. Ek het my kerk lief en het geen klagte daarteen nie, maar julle, Doppers, moet tog nie moeg word as julle honderde myle vir 'n paar lidmate moet aflê nie; julle moet nie daaraan dink om julle kerk op te dok en by ons aan te sluit nie. Dit sal 'n onvergeeflike sonde wees. In julle kerk is daar iets van die siel van die Boerevolk, wat tot niet sal gaan as julle as kerk verdwyn. Dit is ook nergens anders te vind nie. Julle sal ons nie verbeter of versleg nie, want julle is te klein om ons te verander. Die feit dat julle nou meer predikante in Suidwes sal hê sal tot voordeel van die land strek, omdat daar 'n goeie getuienis van julle uitgaan deur middel van julle predikante".

'n Bantoepredikant van die Metodistekerk in S.A., eerw. E. E. Mahabane het die begrafnis van die slagoffers van Sharpeville waargeneem volgens die woorde van Job $1: 21$ nadat hy op lewensgevaar af geweier het om dit ' $n$ politieke begrafnis te maak. Hierdie man het op ' $n$ keer in aanmerking gekom vir die pos van president van 
sy kerk in Suid-Afrika (blank en nie-blank). Hy het op 'n samespreking in Potchefstroom aan ons gesê dat ons Gereformeerdes die goud van God besit en dat ons nie daarop mag bly sit nie en dit aan ander in Suid-Afrika moet meedecl. Hy het ook vertel hoeveel gesonde en waardevolle teologie hy geleer het uit twee jaar se lees van „Die Kerkblad".

Prof. Calvin Seerveld van die Trinity College in Chicago, stel dit as lidmaat van die Christian Reformed Church in Amerika, soos volg: „The religious dynamic which has propelled our civilization is being found wanting! ... Our church has the very critical responsibility of directing and fortifying that confessional life so it helps all the other areas of life flower according to God's ordinances rather than be stunted... We have a store of riches simply unknown to many, many other Christian communions, and a legacy of biblical grit and thoroughness that could win the grudging, implacable hatred of most influential secularists..."

'n Nie-Calvinis, L. Mumford, skryf: „Calvinism was a real attempt to render unto God the things which are Caesar's; a return to that classic republicanism in which civic virtue counted high in the human scale; a return to Christian principles in realms from which it had been progressively banished; a re-union of eternal doctrine and daily deed... It created citizens who were capable of taking over the affairs of state and handling them with a skill that equalled that of the best tyrants, and with a probity that surpassed any earlier political society, even Athens".'

1.2. Waar hierdie rykdomme van God na ons in Suid-Afrika gekom het, vanaf Calvyn se Genève en later veral vanaf Nederland, in besonder vanuit die Gereformeerde Kerken, daar moet ons verder raaksien en besef, dat ons, selfs ten opsigte van hierdie geestelike vaders van ons, vandag in 'n baie gunstiger posisie as hulle verkeer, juis om te getuig teenoor en in die wêreld van vandag.

Waar uiters belangrike en gevaarlike leerverskille steeds meer en meer na vore kom in bogenoemde kerke, is daar as 't ware totale verlamming van kerklike aktiwiteit in sy diepste en vrugbaarste sin en wel omdat geen tug toegepas kan word nie. In plaas van die ou beproefde kerklike weg van tug, praat prof. dr. A. Troost, voorsitter van „Reformatorische Concentratie” (Verontrusting in de Gereformeerde Kerken in een nieu stadium), op hulle eerste vergadering van die volgende programpunte: 'n Eie weekblad; 'n konfessionele modaliteit; ' $n$ skool of kursus vir kategete; noodgemeentes; en 'n derde moontlikheid vir opleiding van predikante (d.w.s. 'n nuwe teologiese skool) - alles binne-in dieselfde kerk, sonder afskeiding. ${ }^{3}$ Dit lyk vir ons alles totaal onmoontlik en onbegryplik. Tog is dit gebore uit die nood van 'n kerk, 'n nood waarin ons tot dusver gelukkig nog nie in verkeer nie.

Dít ook is 'n gawe en rykdom van God, deur die geskiedenis heen. In 1905 het die Gereformeerde Kerke in Nederland 'n verandering aan art. 36 van die Ned. Geloofsbelydenis aangebring en ook ander dogmatiese beslissinge gevel. Dieselfde gebeur in 1926 in 
die sg. Geelkerkensaak, in 1945 en in 1968 waar die besluit van 1926 van Assen herroep is. M.a.w. daar is eers nuwe bindinge bygevoeg by dié van die Drie Formuliere van Enigheid en 'n enkele weggelaat of verander. Later is weer ekstra-konfessionele bindinge vasgestel. Toe dit tot kerkskeuring gelei het, is alles weer herroep. Dit lyk dus van buite af na ' $n$ onsalige geslinger van te veel binding en gesag en dan weer te min, telkens met as gevolg meer verskeurdheid en verdeeldheid. Deur die voorsienige bestel van God het ons in die hele tyd niks by die Konfessie bygevoeg of uitgehaal nie. Van ons kant mag dit deels sondige belydenis-onverskilligheid en teologiese luiheid gewees het, sover dit die mens betref. Die resultaat is egter dat ons die verlamming gespaar is en in eenheid kan saam. leef en saamwerk in een kerk en eendragtig na buite kan getuig. (Interessant en belangrik is cit dat die Christelik-Gereformeerde Kerk in Nederland ook die dinge gespaar is, en dat ons as kerke al hoe nader na mekaar toe beweeg.)

1.3. Prakties beteken die eenheid dat ons nie ons kragte verspil in onderlinge burgeroorlog nie. Verder is ons daarin ryk dat ons drie stelle teoloë het (behalwe ons predikante) in die teologiese professore van Potchefstroom en Hammanskraal, asook dié aan die Potchefstroomse Universiteit vir C.H.O. verbonde. Ons predikante het gemiddeld die laagste aantal lidmate per predikant seker van alle kerke in ons land. Hulle kan dus hulle direkte kerklike werk deeglik doen en nog vrugbaar geleentheid hê vir studie en getuienis. Die samewerking met die Christelike Universiteit is net so 'n rykdom: beide die aangehaalde proff. Troost en Seerveld kla oor die tekort in hulle lande en kerke aan die nodige gelowige kontak tussen die teologie en ander fakulteite, asook die net so nodige verband tussen kerk en wetenskap.

\section{God se openbaring — in 'n verwarde en verdwaalde wêreld}

2.1. Dr. Eugene Carson Blake, opvolger van dr. Visser 't Hooft as hoofsekretaris van die Wêreldraad van Kerke, het op die Uppsalabyeenkoms van die Raad in 1968 gesê: .... that the Church must be willing to support progressive and revolutionary programmes, that nobody today is adequately equipped to lead either a people, a university or a church who is not prepared to take a step into the dark". ${ }^{4}$ Wat hy presies hiermee bedoel het, weet ons nie. In elk geval skyn dit ' $n$ totale negering en ontkenning te wees van God se openbaring in die Skrif as 'n lig op die pad en 'n lamp voor die voet. Vir ongelowige mense mag dit dikwels lyk asof die kerk en die kinders van God die donkerte instap, maar dan is hulle juis siende, siende die onsienlike helder en duidelik soos so heerlik in Hebreërs 11 beskryf.

Iemand wat in die donker tas kan in elk geval nie getuig nie. Hy kan uiters blindelings handel - „moge het treffe" - of anders met 'n hopelose "hoop op sege". Dit is sover as wat die moderne na-Christelike Weste gevorder en verdwaal het en hoe langer hoe meer verward raak. Hierteenoor het God beskik dat ons voorsate 
uit Europa weg is toe die Weste op 'n hoogty van geloof was, kort na die Hervorming. Met die Bybel op die wa en in die hart het hulle die eensame binneland ingetrek en deur Gods genade tot 'n groot mate die geloof behou. Deur hulle isolement is die Bybel in sekere sin ten minste ergens bewaar, waar dit in groot dele van die wêreld feitlik uit die mode geraak het, ten minste onder die geleerdes en leiers van die wêreld. Die plattelandse en natuurlike omgewing waarin die Boerevolk en die Afrikaanse taai grootliks ontstaan het, het moontlik daartoe bygedra dat die Bybel steeds konkreet-histories verstaan en toegepas is. Wanneer die mens in die natuur die bepaalde begin en die duidelike einde van die lewe telkens maar weer sien en ervaar, glo hy des te makliker aan 'n skepping in die begin en 'n voleinding op 'n bepaalde tyd. Net so mag dit vir die verstedelikte mens, wat heel selde die begin en die einde van die lewe sien, makliker wees om aan evolusie te glo - vanuit die moeras na die goddelikheid van die mens, en as dit misluk: van moeras tot riool.

So het die Boer van Afrika dan in sy denke en lewe te staan gekom tussen die sikliese denke van die Bantoeheiden en die vae ontwikkelingsdenke van die ongelowige Westerling. Net soos Kuyper in Nederland in die negentiende eeu besef het dat die Nederlandse Gereformeerde volk nie sal kan standhou sonder 'n eie gelowige universiteit nie, so het ook ons Gereformeerde vaders hier in Suid-Afrika geworstel en gesorg vir 'n Christelike universiteit.

2.2. Om hierdie rykdom van God ten volle te kan benut en ten rykste te kan uitbou, sodat op alle lewensterreine die heldere ligstrale van God se Woord sigbaar kan word, is ten minste twee dinge nodig: die geloof in die Kanon van die Skrif moet gehandhaaf word en die teologiese wetenskap moet waar en suiwer uitgebou word met 'n eie paslike metode.

Die enigste paslike metode om die Skrif te verklaar en sy volle rykdom en diepte van goud te kan ontgin, is die ou Gereformeerde beginsel van: die Skrif verklaar homself. As ons enige ander metode voorop stel en in die Skrif probeer indra dain vermink ons die Openbaring van God en laat dit hoegenaamd nie tot sy reg kom nie. Dit maak nie saak hoe vroom en hoe Skriftuurlik so 'n metode van buite-af bedoel mag word of mag lyk nie. As ons bv., die Openbaring van God in die Kanon gaan beperk tot die sg. kerugmatiese, dan ontneem ons onsself en die kerk van Christus die reg en die materiaal om te getuig oor enige terrein van die lewe, behalwe dié van die saligheid, die redding van die mens se siel. Alte maklik beskuldig ons mekaar van onskriftuurlike-gefilosofeer, sonder om duidelik te bepaal wat ons juis met filosofie bedoel. Die Skrif kanoniseer homself en bepaal ook daarmee uit homself die metode(s) waarmee ons dit moet en kan benader en ontgin. Daarom is die handhawing al dan nie van die Kanon, soos bely in die Nederlandse Geloofsbelydenis, finaal beslissend vir die bepaling van ons metode. Om hiertoe te kom moet ons besef en verstaan dat die teologie as wetenskap deel van die wetenskap in die algemeen is en dat ons baie duidelik vooraf moet onderskei en bepaal wat teologie, logika, filosofie en wetenskapsleer is. ${ }^{5}$ 
Alleen op die wyse kan ons 'n Skrifgelowige teologie uitbou wat nie 'n blote stroois-teologie is nie, d.w.s. 'n enkel, een-verdieping grashuisie wat vir elke gelowige wel voldoende is vir sy saligheid in Jesus Christus, maar wat hoegenaamd nie kan dien as uitgangspunt om te getuig na buite in die Naam van God nie, veral in 'n moderne wêreld waarin al die ander wetenskappe in wolkekrabbers woon en mense met absoluut-noukeurige berekeninge en volkome spanwerk na die maan toe en veilig terug op aarde bring nie. Waar die Gereformeerde Kerken in Nederland in 1905 artikel 36 van die Nederlandse Geloofsbelydenis verander en daarmee in sy strekking totaal vereng het, is eintlik in beginsels die fondament vernietig van alle Gereformeerde getuienis (d.w.s. getuienis in die Lig van God se Woord en nie ,into the dark" nie, vgl. Blake, soos hierbo aangehaal). Waar ons in Suid-Afrika tot drie maal toe die betrokke artikel gehandhaaf het, het ons dus nog die nodige basis, maar mag ons nie voor-wetenskaplik en wetenskaplik daarop gaan lê en slaap nie. Ons moet dit wetenskaplik uitbou soos hierbo genoem, eerste in die teologie en daarna oor alle lewensterreine heen.

2.3. Oortuigend en duidelik toon B. Spoelstra dit histories aan dat die Doppers, buite en binne die Gereformeerde Kerk in Suid-Afrika, altyd tot 'n groot mate vredemakers was, nie ekstremiste nie. Waarom? Omdat hulle geleef en gehandel het uit die Skrif in sy geheel, as Godgegewe Kanon. ${ }^{6}$ Die Gereformeerde teologie moet as wetenskap (prakties en teoreties) in die kerk en daarbuite Skriftuurlik dink, d.w.s. nie in terme van valse teenstellinge wat die wêreld so gereeld in sy denke en praktyk opwerp nie. Die wêreld en die sondaarmens in die kerk, maak alte dikwels soos die een vrou voor Salomo aan wie die lewendige kind nie behoort het nie. Sy het gesê: „Sny middeldeur". Die waarheid in twee gesny is nie twee waarhede nie, nie eers twee halwe waarhede nie, maar twee volle leuens - net soos 'n kind middeldeur gesny nie twee halwe kinders is nie, maar twee stukke lyk. So praat ons bv. agter die wêreld aan van 'n teenstelling tussen logika en liefde en vergeet dat die Woord van God, die Logos, presies identies is met God wat Liefde is. Alle ware liefde is logies en alle ware logika, prakties en teoreties, is volkome liefdevol.

As ons die Skrif s6 in sy geheeì as Kanon aanvaar en daaruit lewe, sal ons getuienis, op elke terrein van die lewe vrede, waarheid en vryheid bring. As ons egter steeds op loop gaan met één puntjie, één aspek, of 'n enkele beperkte konteks' van of in die Skrif, dan word ons sektaries vrugteloos en uiteindelik belaglik. Watter heerlike vrugte mag nie dalk voortvloei uit 'n volledige, gebalanseerde omskrywing van die Skriftuurlike onderskeiding van profeet, priester en koning in verband met die moderne probleme om die regering van die mens, nl. die verhouding van pers, kerk en owerheid nie? Het die jubeljaargedagte van die Ou Testament nie vir ons die beginsel van die oplossing van die moderne ekonomiese probleme en geldmoeilikhede nie, juis soos hulle vasgebrand sit in die valse teenstellirg van ongelowige kapitalisme en anti-Christelike kommunisme nie? Dis juis al hierdie en baie ander moontlikhede wat af- 
en uitgesny word wanneer die Woord van God in die Skrif tot die sg. kerugmatiese beperk word.

2.4. Dikwels hoor ons dat Europa en Amerika ons ver voor is. Dan word ons benoud en wil gou agterna hardloop om nie te ver agter te bly nie. Dan vergeet ons die magtige waarheid van die woord dat as die mense omdraai van hulle dwaalkoers af, na die ou Skriftuurlike waarheid terug, die wat agter gebly het dan juis weer voor is. As ons ouderlinge en diakens, d.w.s. gewone mense in die amp, die kerk nog ywerig dien, is ons op ons outydse manier die wêreld voor wat vandag kerm en kla oor die futiliteit van predikantekerke en dan dikwels vergeefs spartel en spook om die „leke" (gewone lidmate) in die kerk te mobiliseer. Is ons anti-hierargiese Kerkorde uit die Skrif nie dié enigste regte en ware antwoord op die nood van die "wêreldkerke" wat kreun en bly staan onder die dodende las van hulle biskoplike heersers en baie-pratende en niksdoende kollegialistiese sinodes nie? Is hierdie selfde Bybelse Kerkorde nie ook die oplossing van die sg. „rassekwessie” binne-in die kerk nie?

Ons het dié waarhede uit die Skrif, die goud van God, maar ons mag ons daarom nie verhef nie, want ons sondig partykeer, wetend, meer as die ander wat die waarhede nie ken nie.

\section{God se uitverkiesing en roeping - Sy kerk en Sy getuies}

3.1. Dwarsoor die wêreld en orals in die kerk, van buite en van binne, raas en kreun en kerm dit oor die ellendige toestand van die Christelike kerk as instituut, „the institutional church, in failing to preach the Word of God in its central sense, has become internally sick and externally irrelevant". 8 Geen wonder dat selfs 'n Gereformeerde dogmatikus soos Kuitert, meer as onverskillig staan teenoor die instituut en dat 'n Gereformeerde soos Seerveld die gedagte opper dat eintlik al wat instituut is, ontbind moet word om die ware kerk weer in staat te stel om effektief te getuig. Sukkelend spartel die kerk self tussen die pole van „world-flight and -involvement".

In ons eie land vorm sakemanne 'n stigting om van buite af die kerk te help in sy sendingwerk wat hy as instituut nie kan behartig nie. In Duitsland is byna onmiddellik na die einde van die Tweede Wêreldoorlog in 1945 begin met 'n „Evangeliese Akademie" wat beoog het om Duitsland te help heropbou, ,a job not for churchmen, but for laymen. 'God is the Lord of all life, not merely the Lord of a few pious souls congregated weekly - and weakly - in some building on the fringes of life, ... The church must be got out of the church and into the world, every phase of it! ... First and foremost was the need for a 'neutral' meeting-place, one that was neither the haunt of some sepecial group nor under the stained-glass shadow of the institutionalized church". Hierdie Akademie by Bad Boll is reeds bygewoon deur 285000 mense van alle range en stande (o.a. ook Adenauer en Willie Brandt); 5,500 seminare is reeds gehou en daar het nog 15 ander derglike Akademies in Wes-Duitsland, 5 in 
Oos-Duitsland, twee in Johannesburg, twee in Japan en een in Korea ontstaan. ${ }^{9}$

3.2. Moet die kerk van beskeidenheid oor sy vele gebreke as instituut nou maar versand en ontbind en dit aan die mense buitekant die kerk oorlaat om God se getuie te wees op alle terreine van die lewe? Waarom is die mense in die wêreld en in die kerk self so anti-instituut en anti-klerikaal? Is die hoogmoed van die instituut en sy publieke ampsdraers nie die hoof- en allergrootste oorsaak nie, 'n hoogmoed wat des te veragteliker en walgliker was wanneer dit gepaard gaan met woord-ryke totale impotensie om op enige gebied iets werklik-die-moeite-werd uit te voer? Is dit nie omdat die kerk sy eie hart uitgeopereer het nie en niks in die plek daarvan oorgeplant het nie? Waar is die hart van die kerk? Volgens Calvyn is dit die uitverkiesingsleer en -lewe. Hoe kan die instituut en ons as Christene getuies wees daarsonder? Dan moet ons eiegeregtige, hoogmoedige selfaangestelde „volksleiers" word, wat deur die volk verag en verwerp word, of vreesagtige stilblyers, wat of nie gehoor of raakgesien word nie, of verag en verbygegaan word.

3.3. Tle kerk van God kan deur geen mensekind ontbind word nie. Die poorte van die hel sal en kan dit nie oorweldig nie. Dit is gebou op die hoeksteen, Jesus Christus en in Hom onberouelik en onveranderlik van ewigheid af uitverkies, nie net tot die ewige lewe nie, nie net vir die nuwe hemel en nuwe aarde nie, maar ook tot getuie en getuies van Hom op hierdie ou sondige aarde, hier en nou, vandag.

Menslike uitverkiesing mag lei tot hoogmoed, omdat dit noodgedwonge altyd berus op verdienste van die verkorene. Goddellike uitverkiesing is egter gans anders: uit louter genade sonder enige prestasie, voor alle prestasie en dikwels teen alle wanprestasie in. Wie dit in die geloof verstaan en besef, sal nie maklik tot hoogmoed verlei word nie, maar juis in die diepste ootmoed sy rykste krag vind en sy eintlike moed en moed om te getuig. „Hier staan ek, God help my. Ek kan nie anders nie". Dit was die krag en waarheid van alle Gereformeerde, d.w.s. Bybelse getuienis, na binne en na buite, van die gelowiges gesamentlik in die kerk as instituut en van elke gelowige individueel, daar waar God hom/haar stel en roep. So het baie gelowiges van getuies tot martelaars geword - soos die Griekse woord in sy grondbetekenis dit ook duidelik stel. Daarom aspireer die geroepene nie om leier te word en leiding te gee nie, maar is hy of sy bereid om te ly ter wille van die Naam van wie hy getuig. Dus lyers en nie leiers nie, nie opportunistiese self- en publisiteitsoekers nie, maar gehoorsame, dienende ligbringers en soutende sout, meestal stil, onopgemerk.

Die instituut moet en sal voortbestaan as openbaring van die liggaam van Christus, ook as Sy leër, onwrikbaar in sy geroepenheid, onbevreesd, maar steeds beskoue en ootmoedig in die besef van eie ellendigheid, swakheid en sonde. In die instituut moet ons as predikante die Woord bring en as lidmate die gemeenskap van die heiliges beoefen en uitbou; hier is die krag- en ligbron van waaruit 
Jesus Christus die wêreld verower en Sy Koninkryk op aarde vestig, hier en nou, maar ook eenmaal, hiernamaals, volmaak in sy herskape heerlikheid.

\section{God se wêreld en Sy voleinding}

4.1. Dit lê dus nie by die mens om te besluit of daar 'n kerk op hierdie aarde sal wees en bly nie. Die mens moet net getrou en gehoorsaam wees aan sy uitverkiesing en roeping. Hierby moet die kerk en elke gelowige dan net besef en vashou dat die kerk en die hele aarde en almal en alles wat daarop is God se rykdomme is. Satan mag wel tydelik owerste van hierdie wêreld wees, maar dit is en bly 'n gesteelde koningskap. Christus het gekom om dit te vernietig en uit te roei, ook deur middel van Sy getroue diensknegte en diensmaagde.

4.2. Dit beteken dat ons die wêreld net so lief moet hê as wat God dit liefgehad het (Joh. $3: 16$ ). In sy sondigheid sal die wêreld as tydelike eiendom van Satan ons haat, vervolg en selfs doodmaak as dit kan; as geskape eiendom van God en in Christus herskape en die voleinding op Sy tyd en wyse, moet ons dit ken en liefhê. Ons moet daarin nie net die werke en spore van Satan en sy trawante sien nie, maar ook die openbaring van God (bely in artikel 2 N.G.B. en so heerlik beskryf o.a. in Ps. 19). As ons hierdie waarheid nie vashou nie, dan kan ons nie anders as om die wêreld en sy mense (waaronder dan baie uitverkorenes van wie ons nog nie weet nie) totaal te verag nie. Dit maak dienende getuienis onmoontlik 'n Zoeloeonderwyser het een keer gesê: „Jy kan iemand wat jy verag niks leer nie, want hy sien jou hoogmoed dadelik raak en verwerp dan alles wat van jou af kom". Die uitverkiesing is ook hier die band tussen ons as getuies van Christus en die nog-nie-gelowiges wat in die wêreld verkeer: Die uitverkiesing in ons roeping tot taak en arbeid, in en buite die kerk as instituut, is ook die basis van alle struktuurhervorming en kultuuropbou op hierdie sondige aarde. Slegs deur die erkenning en handhawing van die liefde van God in Christus in die antitese en die uitlewing en weerspieëling daarvan in ons denke en dade kan ons waaragtige getuies van Jesus wees en bly en Sy Goeie Boodskap uitdra op alle terreine van die lewe. Hy is kosmies, maar allermins in die sin dat kerk en antitese vernietig moet word om die wêreld by te kom - 'n gedagtegang waarmee baie Christene worstel en wat baie mense in organisasies soos die Wêreldraad van Kerke besighou. Alleen as ons vashou aan God se liefde in die antitese, kan ons Bybel en koerant saam lees, soos Spurgeon aanbeveel het, sonder om die koerant normatief gelyk te stel aan die Bybel en lg. by eg. aan te pas. ${ }^{10}$ Ons moet die wêreld ken om as skerpskutters van Christus raak te skiet en nie vriende in plaas van vyande te dood nie.

Laat ons dan onthou dat die oordeel aan die einde nie net sal lei tot die skeiding van skape en bokke, uitverkorenes en verworpenes, nie maar dat elke daad van elkeen beoordeel sal word. So 
pragtig bely ons dit in artikel 37 van die Nederlandse Geloofsbelydenis op grond van so vele tekste in die Bybel. Laat ons waak dat ons nie gered word as of deur vuur heen nie en dat ons werke (ons getuienis) verbrand word (1 Kor. 3). Openbaringe 17: 14 moet van ons elkeen in die oordeel geld. Laat ons getuig deur Sy Woord en Gees, waar en hoe Hy ons stel en roep.

4.3. Dit beteken in die eerste plek dat ons as uitverkorenes in die amp van gelowige ons volle plig moet doen t.o.v. die kerklike instituut, soos bely in art. 28 van die Nederlandse Geloofsbelydenis en mooi saamgevat in Sondag 38 van die Heidelbergse Kategismus. God dra Sy kerk deur Sy Woord en Gees, maar dit is ook waar dat die kerk as instituut die Woord voort- en uitdra (Rom. $10: 14$ en 15). Mense kan tydelik teer op wat hulle vroeër in die kerk ontvang het (soos onder 3.1. genoem) maar op die lang duur sal die waarheid van die Woord total verdwyn as daar nie 'n instituut is wat dit deur die geslagte heen voortdra en die rykdom daarvan uitbou nie. Daarom moet ons getrou wees in ons prediking, verbondsonderwys en in die gemeenskap van die heiliges soos uiteengesit in ant. 55 van die Heidelbergse Kategismus, sodat die kerk kan groei en bloei en ons goeie werke na buite kan uitstraal as getuienis van Christus.

Vanuit die kerk moet ons daeliks die wêreld ingaan. Van ouds af geld so raak in die wêreld maar nie van die wêreld nie. As predikante moet ons sorg dat ons geen klas vorm in ons klasbehepte wêreld van vandag nie (teenoor die verkeersmanne byvoorbeeld, as ons anti-klas nie). Mense gaan naderhand dieselfde houding inneem teenoor dit wat ons verkondig. Die Kerkorde word dan al te maklik bestempel as 'n soort van mensgemaakte oortreebare verkeersregulasie.

Dit sal miskien goed wees as predikante bietjie minder majesteitlik leef en ook soms per trein of bus reis sodat ons kan sien hoe lyk en praat die gewone man as hy nie sy „predikantgesig" op het nie. Ons prediking moet diep, suiwer en waar wees sodat gelowiges elke Maandag met nuwe lig, moed en krag die wêreld mag ingaan en hulle daelikse werk mag aanpak as getuies van Jesus Christus. Ons almal se huise moet só wees dat seuns aangetrokke voel tot die roeping van predikant sodat die wêreldtekort aan predikante weer aangevul mag word en daar dogters sal wees wat wanneer hulle met predikante trou hulle nie ondermyn nie maar ondersteun.

4.4. Die kerk moet kerk bly en slegs doen wat des kerks is. Die vraag of ons vanuit die kerk in die amp van die gelowige, die wêreld individueel en/of georganiseerd as getuies van Jesus Christus, moet ingaan, sal van geval tot geval, van tyd tot tyd en van plek tot plek in heldere besinning op die Woord beslis moet word. Op die Gereformeerde Ekumeniese Sinode van 1958 het 'n beskrywingspunt oor die saak gedien. ' $n$ Studiekommissie het in 1963 'n volledige en goedgemotiveerde verslag ingedien. ${ }^{11}$ 
Die reeds aangehaalde Mumford skryf soos volg: „Today and Tomorrow. The foreground is dark, and it wil become darker before day breaks. The purging of long-accumulated poisons, the healing of ugly wounds, will not be done in a day; all this needs time, patience, resolute effort, and a willingness to forego selfish local gains for the sake of a larger common good - the unification of mankind and the replenishment of life. Nothing that is worth doing in our and the replenishment of life. Nothing that is worth doing in our time will be done easily; that is, without a spiritual re-birth. Unless the blind recover their sight and the crippled learn to walk our very knowledge will slay us. No peace without struggle; no security without risk; no wholeness without simplification; no goods without measure; no love without sacrifice; no full life without the willingness to accept and transcend death in the very process of living. Those who have learned this lesson may build the City of Man".12

Só skryf en dink en handel die wêreld vir sy Stad van die Mens. Hoeveel meer en hoeveel dieper moet ons delf in die Woord van God onder leiding van die Heilige Gees om op die regte fondament, Jesus Christus, op die regte tyd en op die regte manier ons deel te bou aan die Koninkrylk van God, die Stad Gods?

4.5. Hiertoe moet ons as kerk gesamentlik (sinodaal, klassikaal of gerneentelik) as uitverkorenes en geroepenes in die amp van die gelowiges ook gesamentlik en afsonderlik getuig in die Naam van Christus - in woord, daad en geskrif ten opsigte van politieke en maatskaplike sake. Niemand weet wanneer die einde, God se voleinding, sal kom nie. Daarom moet ons waak en bid en werk, nie optimisties 'n utopie op aarde verwag nie; nie pessimisties laat lê en aan Satan afgee nie met die gedagte dat die ,groot afval" nou al reeds daar is nie. Ons moet nugter gehoorsaam en in die geloof getuig.

Vir hierdie getuienis kan ons eintlik geen algemene reëls en voorskrifte gee nie. Ons kan net stel dat ons nie revolusionêr soos Blake en die Wêreldraad van Kerke mag wees nie. Ons moet Romeine 13 handhaaf en slawe bevry soos Paulus dit met Onesimus gedoen het; nie deur hom met geweld, revolusionêr van sy baas Fileman weg te neem nie, maar deur albei in Christus van die sonde te bevry. Daardeur is na eeue miljoene slawe dwarsoor die wêreld bevry. Ons moet die Skrif as Kanon waaragtig ken en gelei deur die Heilige Gees dat ons ons omgewing waarin ons tot diens geroepe is, waaragtig ken. Ons moet ons deeltjie van God se wêreld ken sodat ons behoorlik tussen vriend en vyand kon onderskei en nie in die wind skiet en praat en handel nie.

Die kerk en die Christen is nie altyd hier op aarde onder die sondebedeling gedoem tot ondergang en neerlaag nie. Ons moet egter oppas dat ons nie soos Moses in haas en woede die rots slaan in plaas van om te praat nie. Ons moet ook waak dat ons nie soos Elia gaan lê met die kleingelowige wanhoopsgedagte dat ek alleen nog as profeet oor is nie. Was God nie bereid om Sodom en Gomorra te spaar ter wille van tien regverdiges nie? Hoeveel organisasies en 
sake is nie al gedra en gered deur een of 'n paar getroue getuigende en werkende Christene nie?

D. C. S. van der Merwe.

(Gelewer voor die Jaarvergadering van die Gereformeerde Teologiese Vereniging te Pretoria, 8-6-71).

\section{AANTEKENINGE:}

a. Kursivering van my. D.M.

b. Verwysings:

1 „Out of concern for the Church. Five Essays", Wedge Publishing Foundation, 1970. Ch. 3 „A Modest proposal for reforming the Christian Reformed Church in North America", p. 48, 61, 66 resp.

2. "The Condition of Man", London, Secker \& Wartburg, 1944, p. 191-2.

3 „Kerknieuws”, 293 jg., no. 1414, 30 April 1971, p. 241 en verder.

4 Aangehaal deur G. C. Oosthuizen in sy "Impressions of Uppsala", in „The Christian Minister", IV-VII, Sept. 1968, p. 3-5.

5 Vollediger uitgewerk in $\mathrm{my}$ "Christelike teologie en Christelike filosofie en hulle onderlinge verhouding", „In die Skriflig”, Jg. 2, nr. 8, Nov. '68.

6 „Die ,Doppers' in Suid-Afrika 1760-1899”, Nasionale Boekhandel, Kaapstad, 1963.

7 Vgl. my resensie van $H$. Wiersinga se "De Verzoening in de theologische Discussie”, „In die Skriflig”, Jg. 5, nr. 18, Junie 1971, p. 56 en verder.

8 "Preface" van die werk onder 1 hierbo genoem, p. 5.

9 a. Kuitert soos aangehaal deur J. H. van Wyk in "Mag die kerk skeur", „In die Skriflig", Jg. 5, nr. 17, Maart 1971, p. 69, noot 48.

b. Dieselfde „Preface" van 8 hierbo, p. 5 en verder J. H. Olthuis in Ch. 5 : „Must the Church become secular?", p. 105 en verder.

c. „Die Burger”, 19/9/70, 22/4/71, 23/4/71 en „Die Kerkblad”, 19/5/71, p. 3.

d. "Reader's Digest”, Mei 1971, pp. 81-85.

10 a. Blake, soos aangehaal in 4 hierbo: „... that the difference between a saint, who represents a certain institution, and a destructive revolutionary is not easy to discern".

b. A. G. Honig: „De kosmische betekenis van Christus”, Kamper Cahiers, no. 7, Kok, Kampen, 1968.

c. H. Wiersinga in sy a.w. onder 7 hierbo.

11 Acta 1958 , art. 28, p. 23-25 en Acta 163, Suppl. 2, p. 92-155, arts. 109117 , pp. 54-58.

12 A.w., onderskrif aan prent teenoor p. 407. 